\title{
PERCEPÇÃO DOS DOCENTES DE BIOLOGIA DO CENTRO DE ENSINO MÉDIO CÔNEGO ADERSON GUIMÃRES JUNIOR, SOBRE O USO DAS TIC'S
}

Samuel da Silva Carvalho ${ }^{1}$, Guilherme Sousa da Silva², Maria Lindalva Alves da Silva $^{3}$, Gonçalo Mendes da Conceição ${ }^{4}$, Heloísa Regina Brito de Sousa ${ }^{5}$

1 Graduado em Ciências Biológicas Licenciatura, do Centro de Estudos Superiores de Caxias, da Universidade Estadual do Maranhã/UEMA (sa-musi@ hotmail.com)

2 Mestrando do curso de Pós-Graduação em Botânica, do Instituto Nacional de Pesquisas da Amazônia, INPA, Manaus-AM.

3 Mestranda do Programa de Pós-Graduação em Biodiversidade, Ambiente e Saúde/PPGBAS, do CESC/UEMA

4 Professor Doutor da Universidade Estadual do Maranhão, do Programa de Pós-

Graduação em Biodiversidade, Ambiente e Saúde/PPGBAS, Caixa Postal 027

Teresina/Piauí, Brasil

5 Graduada em Ciências Biológicas Licenciatura, do Centro de Estudos

Superiores de Caxias, da Universidade Estadual do Maranhão/UEMA

Recebido em: 08/04/2017 - Aprovado em: 10/06/2017 - Publicado em: 20/06/2017 DOI: 10.18677/EnciBio_2017A141

\begin{abstract}
RESUMO
As tecnologias da informação são ferramentas com potencial transformador para promover a equidade e qualidade na educação. Nesta perspectiva, o docente busca alternativas que visem conciliar as mídias ao cenário educacional. O presente trabalho objetivou analisar as perspectivas dos docentes quanto ao uso das tecnologias da informação e comunicação no C.E. Conego Aderson Guimarães Júnior. Para realização da pesquisa e obtenção dos dados, foram selecionados seis professores de Biologia da escola, aos quais foram submetidos a um questionário socioeducativo para analisar a visão dos mesmos quanto ao uso das TIC's no ambiente escolar. Após análise dos dados, observou-se que os docentes da escola utilizam recursos midiáticos na prática educativa e no cotidiano escolar, contudo ressaltam que pontos como a falta de interesse dos alunos e de estrutura, dificultam a prática pedagógica quanto ao uso das TIC's. Notou-se também que os docentes possuem uma percepção dicotômica quanto avaliação do uso das TICs na escola, mostrando-se necessitados de um curso de aperfeiçoamento e manejo das TIC's. Assim o presente trabalho mostra a necessidade que os docentes de Biologia possuem em utilizar os meios tecnológicos que auxiliam no processo de ensino aprendizagem dos alunos, visando a prática pedagógica dentro do ensino de Biologia e principalmente em sala de aula.
\end{abstract}

PALAVRAS-CHAVE: Educação, Ensino de Biologia, Recursos didáticos. 


\title{
PERCEPTION OF TEACHERS OF BIOLOGY AT THE MIDDLE SCHOOL EDUCATION CENTER ADERSON GUIMÃRES JUNIOR, ON THE USE OF TIC'S
}

\begin{abstract}
Information technologies are tools with transformative potential to promote equity and quality in education. In this perspective, the teacher seeks alternatives that aim to reconcile the media to the educational scenario. The present work aimed to analyze the perspectives of teachers regarding the use of information and communication technologies in C.E. Conego Aderson Guimarães Júnior. In order to carry out the research and obtain data, six school biology teachers were selected, who were submitted to a socio-educational questionnaire to analyze their vision regarding the use of ICT in the school environment. After analyzing the data, it was observed that the teachers of the school use media resources in the educational practice and in the school routine, but they point out that points such as the lack of interest of the students and of structure, make difficult the pedagogical practice regarding the use of the TIC's. It was also noted that teachers have a perception regarding the evaluation of the use of ICTs in school, showing a need for a course of improvement and management of ICTs. Thus the present work shows the need that Biology teachers have in using the technological means that help in the process of teaching students' learning, aiming the pedagogical practice within the teaching of Biology and especially in the classroom.
\end{abstract}

KEYWORDS: Education, Teaching of Biology, Didactic resources.

\section{INTRODUÇÃO}

As Tecnologias de Informação e Comunicação - TIC's são um conjunto de recursos tecnológicos que, ao serem agregados entre si, proporcionam uma melhoria na comunicação frente a diversos processos existentes nas atividades profissionais, no ensino e na pesquisa científica (OLIVEIRA et al., 2015). No contexto do ensino aprendizado, as TICs têm uma importante função como base pedagógica para auxiliar na melhoria do ensino, desde da educação básica ao ensino superior (ALBINO \& SOUZA, 2015).

A inserção desses meios tecnológicos no ambiente escolar pode provocar transformação efetiva e qualitativa, todavia podem não assegurar resultados tão satisfatórios, pois, a inclusão das mídias remete a profundas mudanças nas práticas pedagógicas refletindo na realidade educacional, onde os docentes buscam associar o método tradicional com as TIC's para a construção do conhecimento, não se prendendo somente a transmissão, mas a reciprocidade entre docente e discentes dentro da sala de aula (COSTA, 2011; OLIVEIRA et al., 2015).

Neste contexto o ensino de ciência mostra-se carente no que diz respeito a praticas voltadas a inserção de tais meios de comunicação, onde o ensino de Ciências na Educação Básica e na formação do professor de Ciências sofre, historicamente, múltiplas influências principalmente por parte da tradição escolar (FRISON et al., 2012). Mesmo com todo esse atraso no campo das ciências, principalmente no campo da Biologia, pode-se observar as diversas transformações das mesmas na comunidade cientifica e pedagógica, procurando acompanhar as mudanças tecnológicas para a melhoria do ensino aprendizado de Ciência e Biologia (COSTA, 2011).

O ensino de Biologia, dentro do cenário da educação brasileira, destaca-se por acompanhar as mudanças científicas e tecnologias no campo da ciência. Constitui-se de diversos conteúdos em sua grade curricular, dentre eles, os 
conteúdos de Botânica, que apresentam várias dificuldades, pois a maior parte dos professores demonstram descaso, fazendo com que os alunos não compreendam os conteúdos e na maioria das vezes apresentam aversão ao conhecimento (MELO et al., 2012). Vale ressaltar que esta aversão está relacionada a fatos como: desinteresse dos alunos, resultante principalmente de conversas paralelas, desatenção e uso do celular na sala de aula, o que dificulta a aprendizagem dos próprios alunos (SILVA et al., 2011; CARVALHO et al., 2016). O ensino de Biologia traz contribuições para o conhecimento de processos biológicos e científicos através de inúmeras tecnologias para o desenvolvimento humano, despertando assim um interesse real do aluno para a realidade da vida (OLIVEIRA, 2013).

Para auxiliar os docentes na tarefa de fazer com que os alunos encontrem o entendimento sobre o que está sendo estudado, acredita-se que as TIC's, se bem utilizadas, podem ser uma aliada importante no ensino aprendizagem (BARBOSA et al. 2015). Com esta perspectiva, analisando a importância de se discutir a utilização das tecnologias de informação e comunicação no ressinto educativo, procurou-se investigar as que são empregadas por docentes da escola C.E. Cônego Aderson Guimarães Júnior em suas aulas e tomar conhecimento da percepção desses docentes no que diz respeito às vantagens e desvantagens que o uso das TIC's causam dentro da prática pedagógica e consequentemente no ensino aprendizado.

\section{MATERIAL E MÉTODOS}

A pesquisa baseou-se numa abordagem qualitativa descritiva, a qual se caracteriza pela vivência direta do pesquisador na realidade estudada, visando conhecê-la com mais intensidade além de buscar investigar através de questionário a percepção dos docentes de Biologia quanto ao uso dos recursos midiáticos em sala de aula e pela escola. Para a realização da pesquisa foi selecionado o C.E. Cônego Aderson Guimarães Júnior, onde foi apresentado à escola um termo de consentimento para realização das ações.

Esta instituição de ensino médio que pertence a rede estadual de ensino atendeu à 710 alunos em 2016, segundo informações cedidas pela Coordenadora Pedagógica. A escola está sediada na Rua Arão Reis, Centro de Caxias - MA com CEP: 65604-060, em relação as demais instituições da rede estadual, a mesma não apresentava nenhum projeto pedagógico sobre a temática dos recursos midiáticos.

A pesquisa teve duração de sete meses, iniciando em Dezembro de 2015 a Junho de 2016. Foram entrevistados os seis docentes da disciplina de Biologia da escola através de questionários apenas com questões objetivas, este questionário contou com 10 questões abrangendo o perfil socioeducativo e das metodologias aplicadas em sala de aula buscando analisar a visão destes docentes sobre o uso da TICs no ambiente escolar (APÊNDICE A). Os professores entrevistados ministravam aulas nas turmas de $1^{\circ}$ ao $3^{\circ}$ da escola distribuídos nos turnos matutino, vespertino e noturno. Foi feita a análise comparativa dos dados obtidos, realizando medidas percentuais de cada questão respondida pelos docentes, elaborando gráficos através do programa Microsoft Office Excel 2013, para melhor visualização e discussão dos dados.

\section{RESULTADOS E DISCUSSÃO}

No que diz respeito ao gênero dos docentes de Biologia que atuam no C. E. Cônego Aderson, os seis professores entrevistados são do sexo masculino. Quanto à idade apresentada pelos professores de Biologia atuantes na instituição de ensino, a maioria está na faixa etária entre 31 a 40 anos, totalizando $50 \%$ dos docentes 
entrevistados, $25 \%$ possuem de 20 a 30 anos e $25 \%$ estão na faixa etária dos 41 a 50 anos de idade.

Quanto à quantidade de tempo em que os professores entrevistados atuam na área da docência (Figura 1), 50\% atuam de um a 10 anos, 25\% atuam de 20 a 30 e $25 \%$ atuam de 30 a 40 anos no ambiente escolar. Estes dados mostram que os percentuais de docentes de Biologia com menos tempo de experiência são iguais aos mais experientes. CAMPOS \& DINIZ (2001), trabalhando com sete docentes de Biologia, apresentaram resultados semelhantes ao deste estudo, os professores também apresentaram a faixa de um a 10 anos que atuam na área. GABARDO \& HOBOLD (2011), em estudo sobre os perfis dos docentes quanto ao período que estes atuam em sala de aula, revelaram que as diversas etapas que os professores passam bem como analisaram a prática docente quanto à constituição de uma identidade profissional estabelecendo uma relação do período de docência destes profissionais com a postura assumida ao longo de suas carreiras. Pelos resultados do tempo de docência dos professores ficou evidenciado um equilíbrio entre os profissionais mais e menos experientes, facilitando a interação entre os mesmos e a troca de experiências quanto ao uso de metodologias aplicadas em sala de aula.

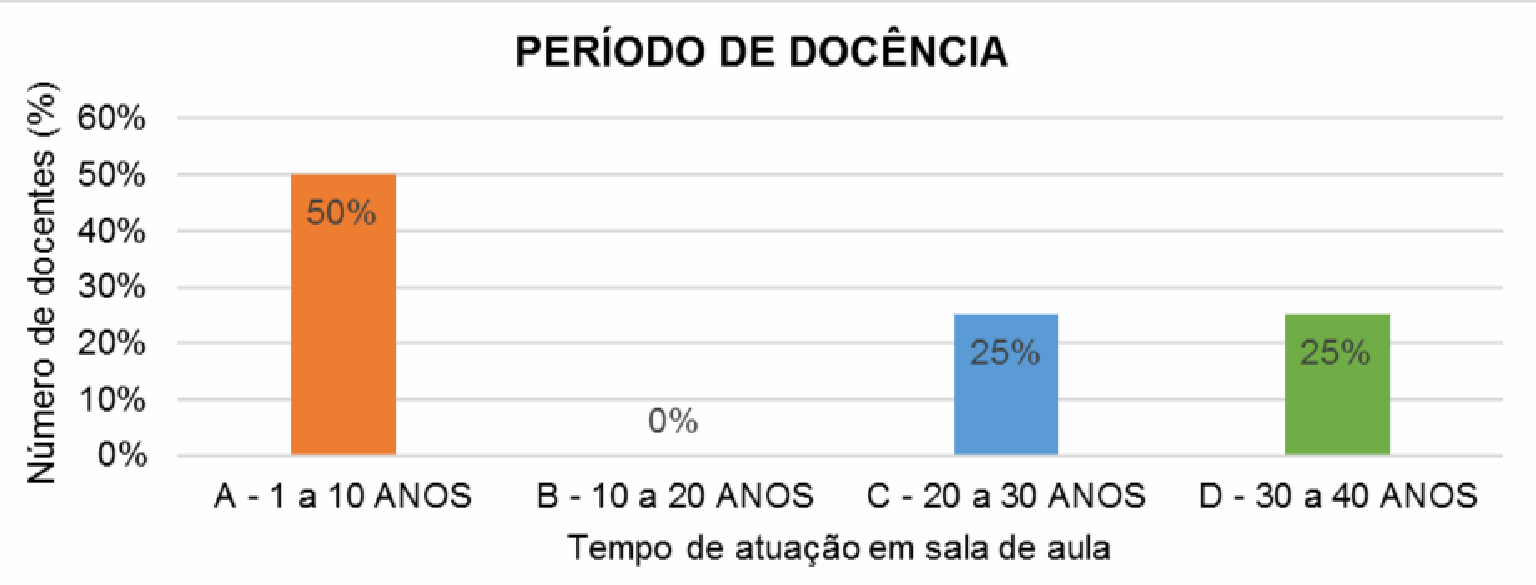

FIGURA 1 - Período de docência dos professores de Biologia.

Quanto ao tempo em que os docentes de Biologia estavam na escola, $75 \%$ afirmaram lecionar de um a 10 anos e 25\% lecionam de 11 a 20 anos (Figura 2). Nota-se que a maior parte dos professores de Biologia atuam a um bom tempo na escola, fato que pode contribuir com a aprendizagem dos alunos uma vez que não há uma rotatividade dos professores, facilitando dessa forma, a construção de uma base sólida no que tange a metodologia do docente e o desempenho do aluno na sala de aula. ZARANZA (2014), ao trabalhar com análise da rotatividade de professores de uma escola de ensino médio do Ceará, mostrou que na área das Ciências naturais há uma troca constante de docentes, além de comprovar maior carência de docentes habilitados na disciplina, intensificando o fenômeno da rotatividade do trabalho de professores na escola pública de Ensino Médio. Os dados deste estudo revelaram que a rotatividade dos docentes de Biologia do C.E. Cônego Aderson Guimarães Júnior não é frequente evitando a carência e segregação de professores na escola. 


\section{QUANTO TEMPO LENCIONA NA ESCOLA}

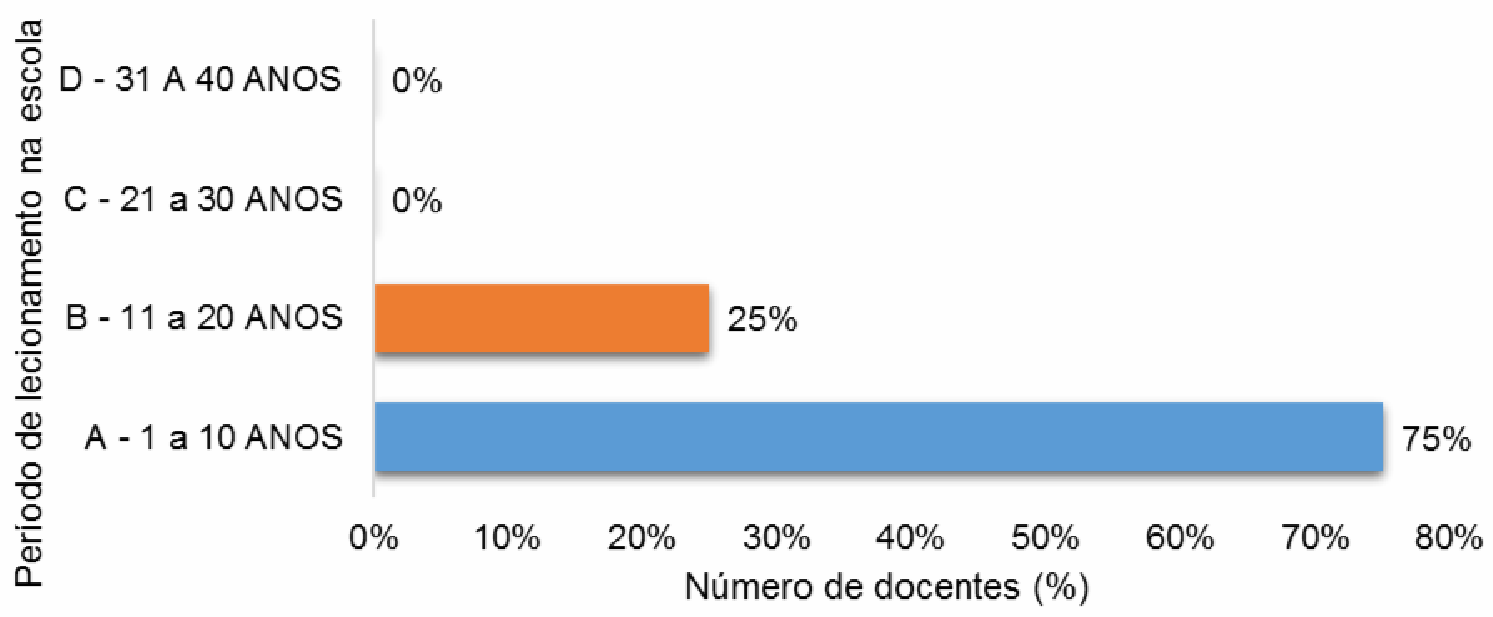

FIGURA 2- Período em que o docente de Biologia leciona na escola.

Em relação ao uso exclusivo do livro didático em sala de aula, $50 \%$ dos professores não utilizam somente esse recurso, sempre que possível tentam fazer uso de outras técnicas durante as aulas, $25 \%$ permanecem presos a esse recurso e no modo tradicional de ministrar aulas, enquanto que $25 \%$ optam por utilizá-lo somente às vezes, pois recorrem a outros meios (Figura 3 ). $\mathrm{O}$ livro didático é um instrumento importante para o ensino formal e apesar de não ser o único material que possa ser utilizado em sala de aula, é uma ferramenta decisiva para a qualidade do aprendizado advindo do ambiente escolar (LAJOLO, 1996).

Logo, esta ferramenta pedagógica, é de suma importância para o aluno, devido a sua acessibilidade e disponibilidade, e para o docente, no auxílio de suas atividades. SOARES (2002) salienta que o professor vê o livro didático apenas como uma das ferramentas entre tantas outras capazes de Ihes propiciar condições de ministrar um ensino de qualidade, e que na prática docente, o livro didático não deve ser visto como um manual a ser seguido. Embora facilite a atividade do professor, não deve ser o centro das atividades de ensino, mas um material de apoio, pois com a quantidade de recursos disponíveis no mercado, o professor precisa sair da sua zona de conforto e utilizar outros recursos que atraia a atenção do aluno tornando a sala de aula um ambiente mais prazeroso.

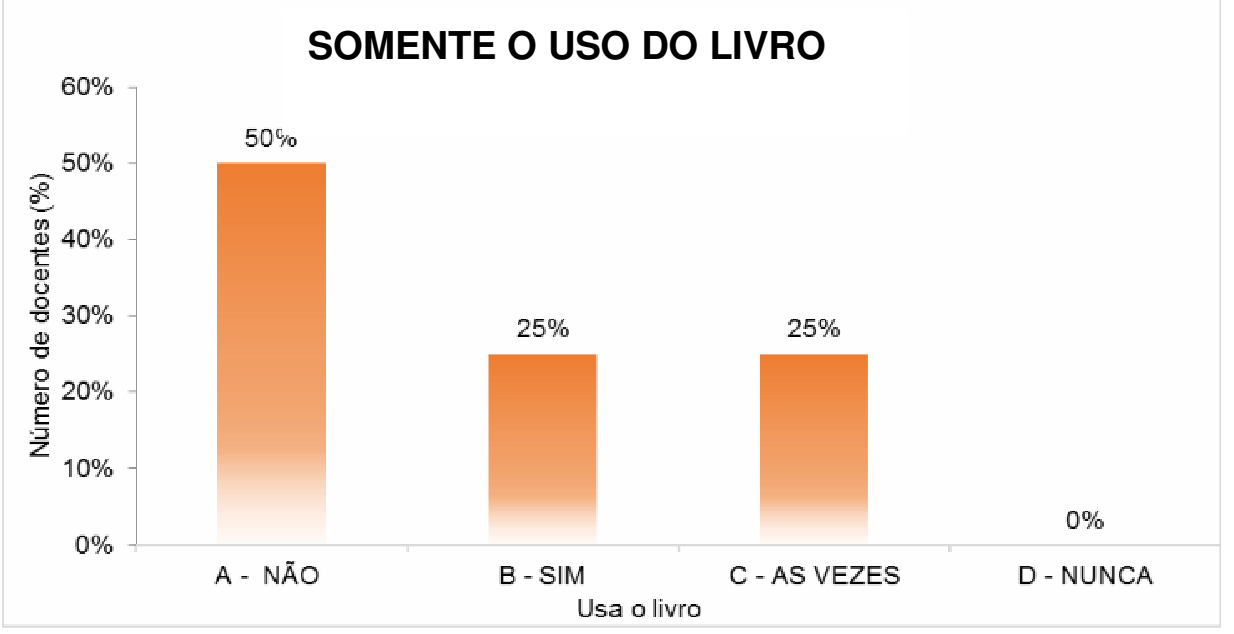

FIGURA 3 - Somente a utilização do livro didático. 
Ao serem questionados quanto ao uso de outros recursos além do livro $50 \%$, dos docentes afirmaram fazerem uso de computadores e $50 \%$ outros meios que facilitem a interpretação do conteúdo, como maquetes, jogos e dinâmicas (Figura 4), ou seja, os professores de Biologia procuram outras formas para subsidiar o ensino. Segundo SILVEIRA (2001), a sociedade contemporânea é marcada pela variedade de linguagens, em virtude da constante inclusão de meios de comunicação, onde a adequação de práticas de ensino visam melhorar a qualidade do ensino aprendizado, explorando a utilização das imagens, movimentos, músicas e artes, criando um mundo imaginário que retome a realidade que será trabalhada nos conteúdos em sala de aula. De acordo com os Parâmetros Curriculares Nacionais BRASIL (2000, p.11-12):

As Novas Tecnologias da Comunicação e Informação-TICs permeiam o cotidiano, independente do ambiente físico, criando necessidades de vida e convivência que precisam ser analisadas no espaço escolar, deixando evidente que os meios tecnológicos, aproximou os homens à outra realidade através de imagens e sons de mundos antes inimagináveis.

À luz dos PCNs e dos teóricos o uso da informática na escola, bem como, de outros recursos que venham subsidiar a aprendizagem dos alunos na perspectiva de proporcionar um ensino voltado para o contexto social e cultural dos discentes que atinja seu objetivo proposto que é a formação de cidadãos críticos e conscientes atuando numa sociedade justa e igualitária (BRASIL, 2000).

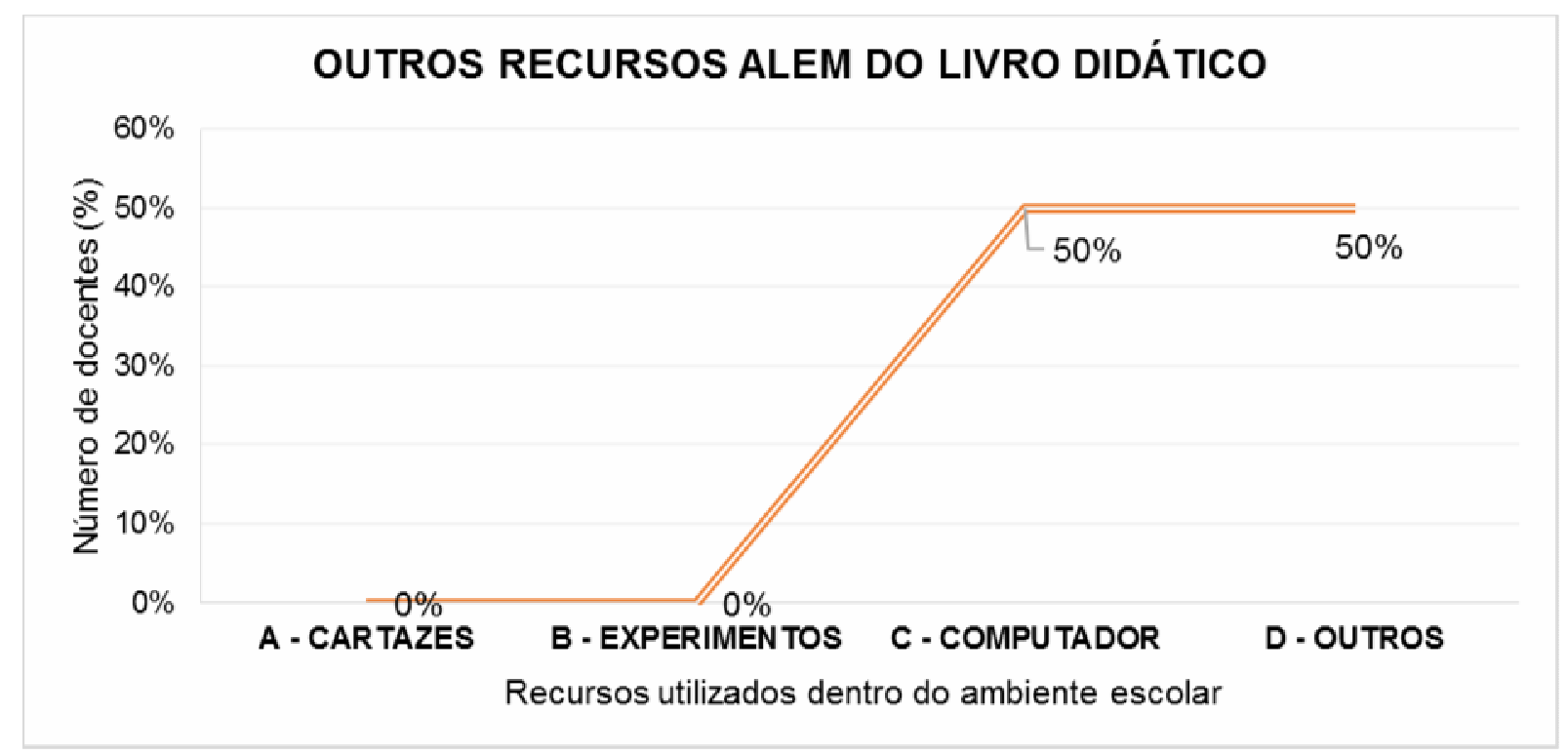

FIGURA 4 - Outros recursos utilizados além do livro didático.

No que diz respeito as dificuldades enfrentadas em sala de aula, quanto ao aspecto, ensino e aprendizagem, docentes destacaram a falta de estímulos dos alunos pelos conteúdos de Biologia, correspondendo a $75 \%$. A falta de material didático foi outro aspecto analisado pelos docentes entrevistados, correspondendo a $25 \%$ na opinião dos pesquisados (Figura 5). Existem vários fatores vivenciados pelos docentes em todas as áreas de ensino, porem dentre os problemas mais evidentes na Botânica, está a falta de interesse por parte dos estudantes por esse ENCICLOPÉDIA BIOSFERA, Centro Científico Conhecer - Goiânia, v. 14 n.25; p.1705 
conteúdo, pois segundo KINOSHITA et al. (2006), apesar de muitos motivos serem apontados para tal desinteresse o ponto fundamental parece ser a relação que nós seres humanos temos com as plantas, ou melhor, com a falta de relação que temos com elas, ainda na visão de MENEZES et al. (2008),o fato desses seres não interagirem diretamente com o homem e serem estáticos, ao contrário dos animais, pode justificar o distanciamento dos estudantes.

Por trás desse desinteresse apontado pela maioria dos docentes notam-se diversos problemas que dificultam a prática pedagógica como, as condições da estrutura física do prédio escolar, metodologias aplicadas em sala de aula, condições dos recursos didáticos disponíveis, dentre outros. Segundo MADALÓZ et al. (2012), esses critérios são preponderantes quando se analisa o grau de interesse e participação dos alunos na sala.

\section{DIFICULDADES ENCONTRADAS PELOS PROFESSORES DE BIOLOGIA}

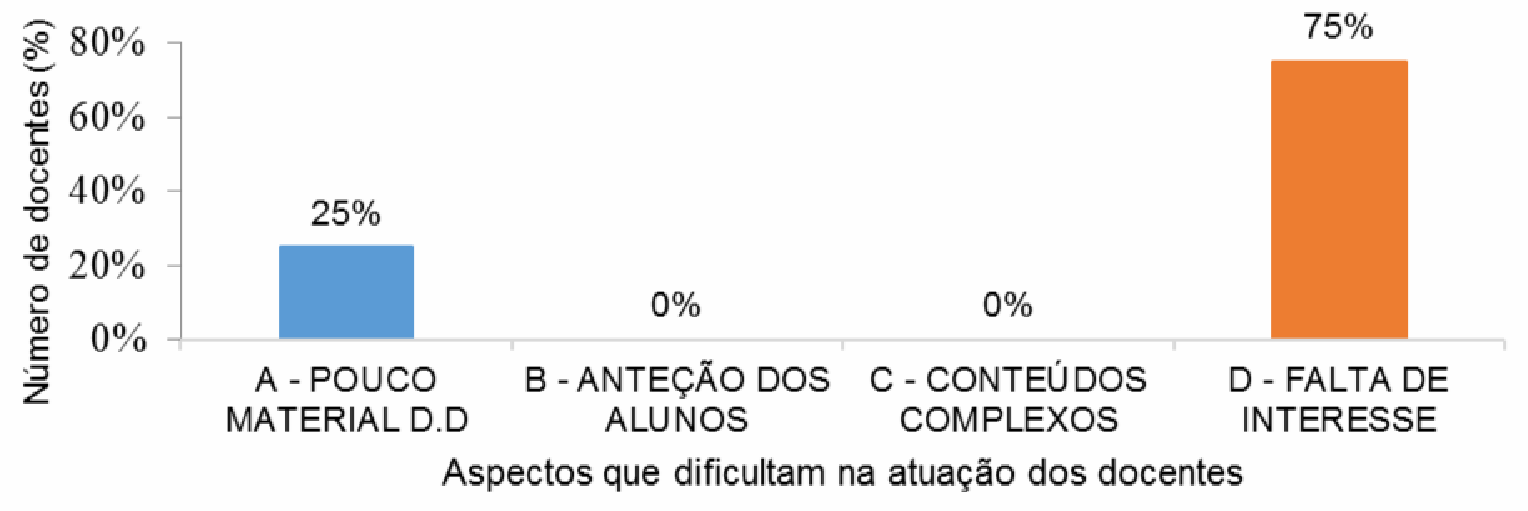

FIGURA 5 - Dificuldade dos professores de Biologia para ministrar suas aulas.

Neste estudo também foi abordado aos professores de Biologia como eles avaliavam o uso das TICs na escola, $50 \%$ dos professores achavam regular a utilização das TICs na escola, os outros $50 \%$ apontaram como péssima (Figura 6), pois segundo o relato dos mesmos, muitos equipamentos estão danificados, passando por constantes reparos, principalmente no laboratório de informática.

Observa-se que há uma dicotomia no resultado do gráfico da Figura 6, quanto ao percentual, pois metade dos docentes discordam quanto à avaliação do uso dos recursos midiáticos afirmando que são regulares $(50 \%)$ e a outra metade como péssimas $(50 \%)$, estas informações evidenciam a necessidade de um consenso entre estes docentes e para que isso aconteça é necessário a realização de cursos de capacitação nivelando assim o grau de conhecimento quanto as TIC's e que mostre à importância do recurso não apenas para os docentes da área de Biologia, mas como todo o grupo da escola. Para STAHL (2000), os cursos de capacitação continuada de professores nas escolas são importantes e devem proporcionar aos futuros e atuais professores variadas experiências com as novas tecnologias, podendo contribuir, a partir da análise do contexto em que vão ser inseridas. 


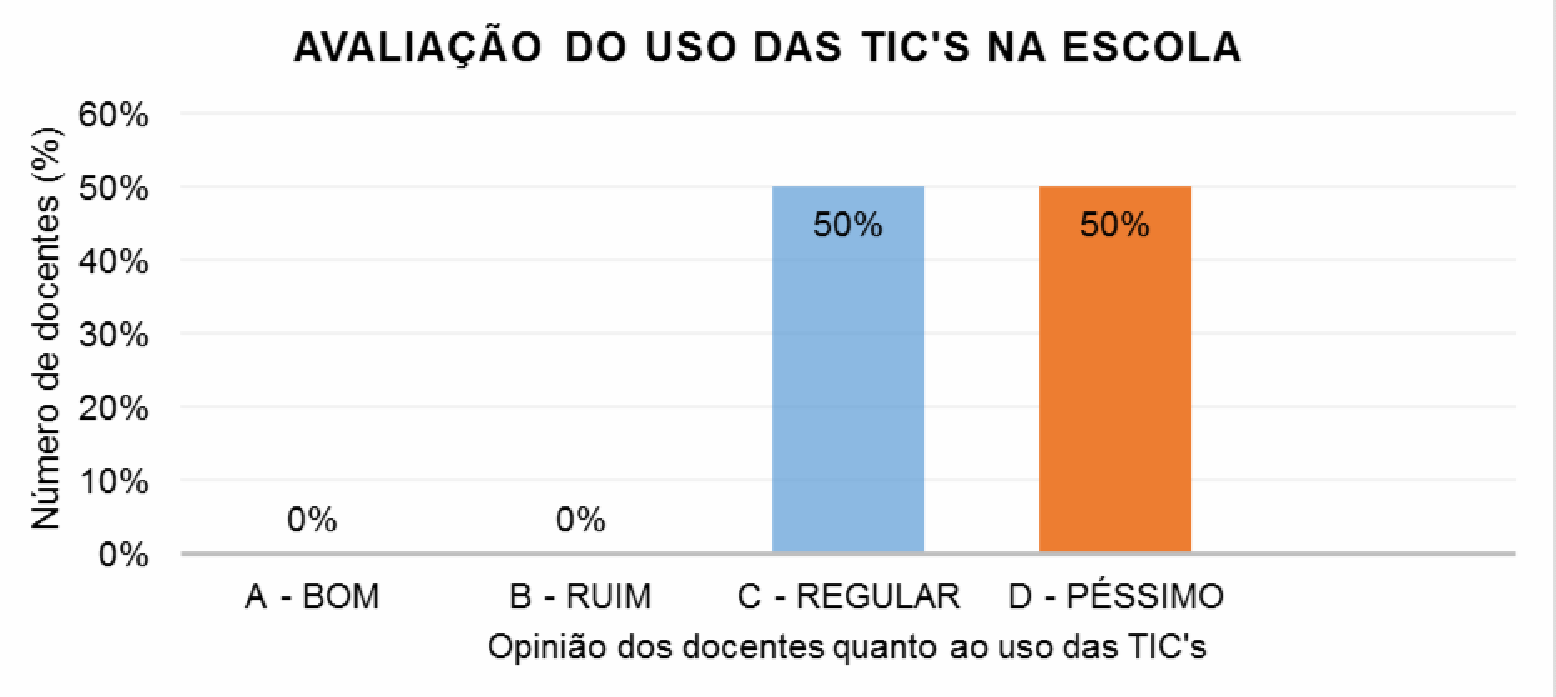

FIGURA 6 - Avaliação do uso das TICs na escola.

Também foi analisada a visão que estes docentes têm sobre o uso dos recursos midiáticos pelos profissionais de outras disciplinas da escola (Figura 7), $75 \%$ dos professores afirmaram que semanalmente acompanham a utilização desses recursos como auxiliadores em suas aulas pelos seus colegas e $25 \%$ afirmaram que nunca observaram a utilização pelos seus colegas em sala de aula. De acordo com GOMES (2014), a aplicação dos recursos midiáticos adota uma linguagem acessível e inovadora, através não só da prática do ensino de Ciências, mas também, dentro das outras áreas de ensino, acabando por exigir do telespectador (aluno), maior atenção e envolvimento durante o período de estudo, por se tratar de uma estratégia dosada em tempo, sendo este um dos fatores que acaba por chamar atenção dos mesmos por meio dos efeitos, imagens, vídeos, sons e escritas.

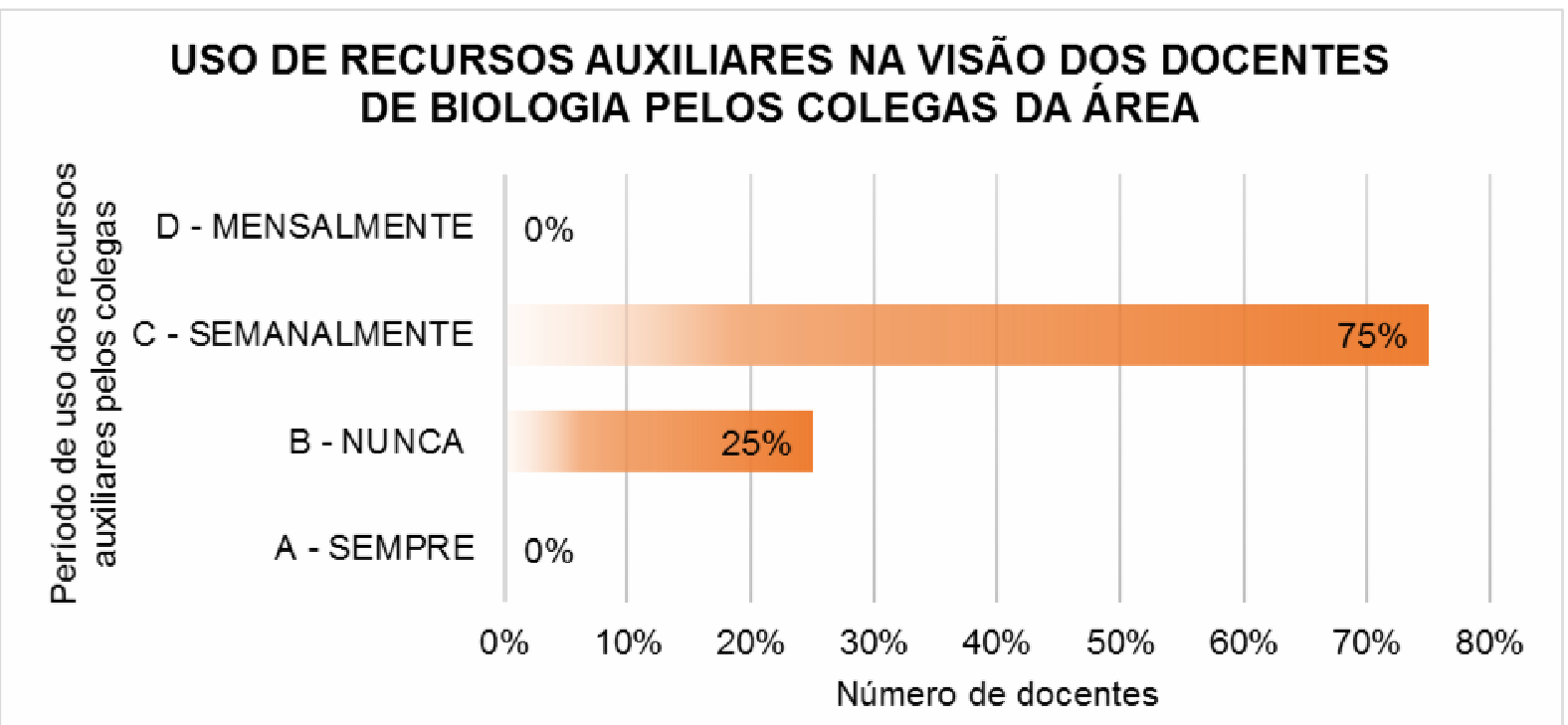

FIGURA 7 - Uso de Recursos Auxiliares na visão dos docentes de Biologia pelos seus colegas. 
Por último foi questionado como os docentes de Biologia avaliam do ponto de vista pedagógico da escola a utilização das TICs. Os docentes mostraram através dos dados como era a relação pedagógica estabelecida entre a escola, professor e aluno, $25 \%$ acham bom, $50 \%$ apontam como regular e outros $25 \%$ como péssima (Figura 8). THOALDO (2010), ao fazer um levantamento sobre o uso das TICs em sala de aula através de questionários com professoras dos anos iniciais do ensino fundamental, apontou que a relação tecnologia educacional e a prática pedagógica pode vir a colaborar, desde que a tecnologia seja subjugada aos objetivos pedagógicos, para que haja um melhoramento no ensino, mas, exigindo uma formação, maior envolvimento e o compromisso dos docentes no processo de ensino aprendizagem. Os dois últimos dados são respondidos pelo fato de que no período de aplicação do Projeto Político Pedagógico - PPP da escola passava por revisão e reestruturação e muitas das metas estabelecidas no campo pedagógico da escola quanto ao uso do Laboratório e práticas educativas estavam em análise.

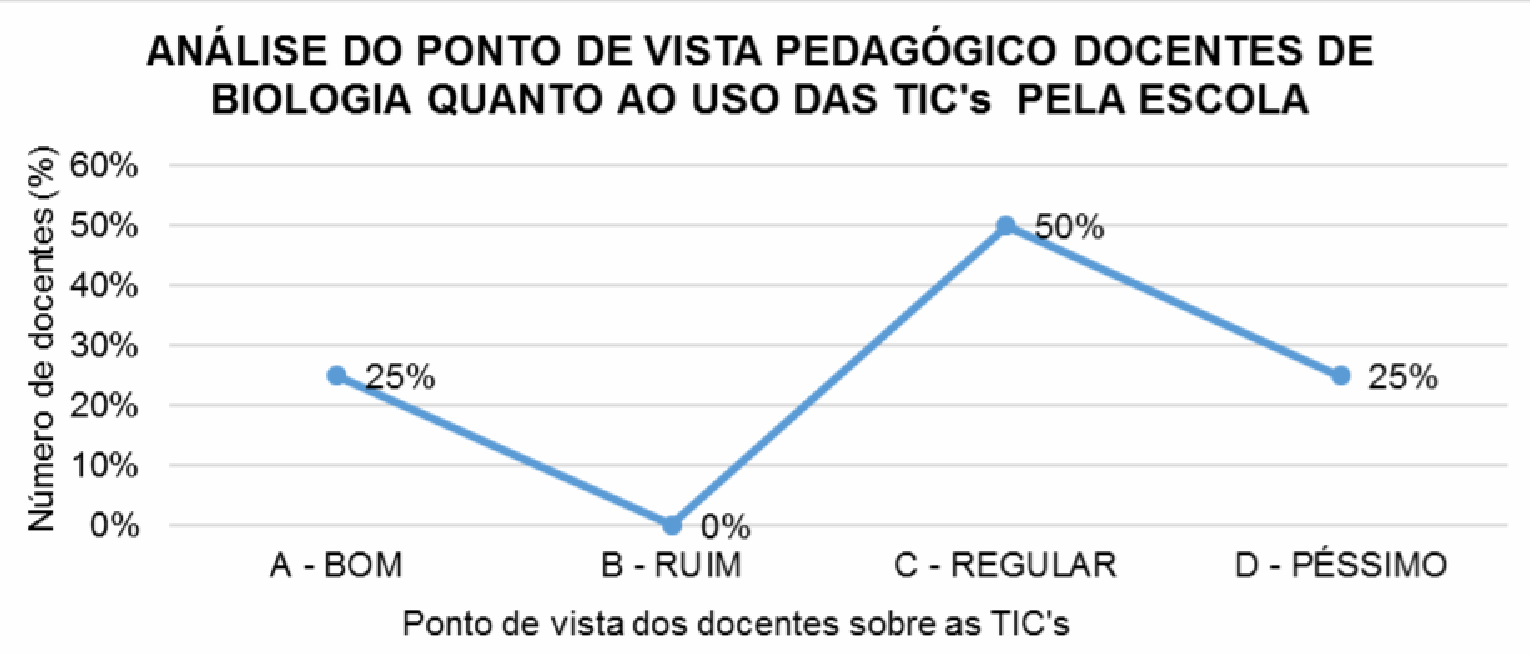

FIGURA 8 - Análise do ponto de vista pedagógico dos docentes de Biologia quanto ao uso das TICs pela escola.

\section{CONCLUSÃO}

O presente trabalho é de grande importância quanto ao uso das tecnologias da informação e comunicação, pois permitiu que os professores repensassem em suas metodologias aplicadas em sala de aula. Notou-se também que, os docentes possuem uma percepção variada em relação a inserção e utilização dos recursos midiáticos dentro do ambiente escolar e a grande carência estrutural que sofrem ao mostrarem como a intervenção midiática pode auxiliar no processo de ensinoaprendizagem.

\section{AGRADECIMENTOS}

À Universidade Estadual do Maranhão/UEMA, pela formação e fomento do projeto; à Proexae/UEMA pela concessão da bolsa de Extensão; ao Laboratório de Biologia Vegetal/LABIVE pelo apoio em todas as etapas da pesquisa, ao C.E Cônego Aderson Guimarães Junior pela parceria, aos docentes de Biologia que aceitaram participar da pesquisa.

\section{REFERÊNCIAS}

ALBINO, R. D.; SOUZA, C. A. Avaliação do nível de uso das TICs em escolas brasileiras: Uma exploração dos dados da pesquisa "TIC Educação". XXXIX ENCICLOPÉDIA BIOSFERA, Centro Científico Conhecer - Goiânia, v.14 n.25; p.1708 2017 
Encontro da ANPAD-XXXIX/ EnANPAD. Belo Horizonte / MG. p. 17, 2015. Disponível em: https://webcache.googleusercontent.com/search?q=cache:JgVM4jj-kEJ:https://ufrr.br/administracao/index.php\%3Foption\%3Dcom_phocadownload\%26v iew\%3Dcategory\%26download\%3D178:tic-educacao\%26id\%3D28:tema 9\%26ltemid\%3D232+\&cd=3\&hl=pt-BR\&ct=clnk\&gl=br. Acesso em: 28/03/2017.

BARBOSA, P. P.; MACEDO, M.; BUENO, C. A.; URSI, S. As Tecnologias de Informação e Comunicação e o ensino: como professores de Biologia têm utilizado animações?.X Encontro Nacional de Pesquisa em Educação em Ciências - X ENPEC Águas de Lindóia, SP. p. 8, 2015. Disponível em: www.abrapecnet.org.br/enpec/x-enpec/anais2015/resumos/R1079-1.PDF. Acesso em: 29/03/2017.

BRASIL. MEC - Ministério da Educação. Parâmetros Curriculares Nacionais Ensino Médio. Brasília: MEC/Secretaria de Educação Básica, p. 109, 2000. Disponível em: portal.mec.gov.br/seb/arquivos/pdf/blegais.pdf. Acesso em: 28/03/2017.

CAMPOS, L.M. L; DINIZ, R. E. S. A Prática como fonte de Aprendizagem e o saber da Experiência: o que dizem Professores de Ciências e de Biologia. Investigações em Ensino de Ciências. v. 6, n. 1, p. 79-96, 2001. Disponível em: https://www.if.ufrgs.br/cref/ojs/index.php/ienci/article/view/587. Acesso em: 23/02/2017.

CARVALHO, S. S.; SILVA, G. S.; SILVA, M. L. A.; CONCEIÇÃO, G. M. Uso Do Programa Power Point Como Ferramenta Na Disciplina De Biologia - Botânica Do Ensino Médio Na Cidade De Caxias, Maranhão. Enciclopédia Biosfera, Centro Científico Conhecer - Goiânia/GO, v.13 n.23; p. 11, 2016. Disponível em: http://www.conhecer.org.br/enciclop/2016a/ciencias\%20humanas/uso\%20do\%20pro grama.pdf. DOI: 10.18677/Enciclopedia_Biosfera_2016_161. Acesso em: 28/03/2017.

COSTA, M. V. Material instrucional para ensino de Botânica: cd-rom possibilitador da aprendizagem significativa no ensino médio. Universidade Federal de Mato Grosso do Sul. Centro de Ciências Exatas e Tecnologia: Programa de Pós-graduação em Ensino de Ciências Mestrado em Ensino de Ciências II, Campo Grande-MS. p. 148, 2011. Disponível em: https://sistemas.ufms.br/sigpos/portal/trabalhos/download/251/cursold:94. Acesso em: 29/03/2017.

FRISON, M. D.; VIANNA J.; RIBAS, F. K. Ensino de Ciências e Aprendizagem Escolar: Manifestações sobre Fatores que Interferem no Desempenho Escolar de Estudantes da Educação Básica. IX ANPED SUL - Seminário de Pesquisa em Educação da Região Sul. p. 10, 2012. Disponível em: https://www.researchgate.net/file.PostFileLoader.html?id=57ff757193553bf72b3f02c2 \&assetKey=AS\%3A416696667000832\%401476359635179. Acesso em: 28/02/2017.

GABARDO, C. V; HOBOLD M. S. Início da docência: investigando professores do ensino fundamental. Formação docente Revista brasileira. Form. Doc., Belo Horizonte, v. 3, n. 5, p. 85-97, 2011. Disponível em 
http://formacaodocente.autenticaeditora.com.br. ISSN: 2176-4360 Acesso em: 07/06/2016.

GOMES, J. H. Utilização dos Recursos Midiáticos como Estratégias de Aprendizagem no Ensino de Ciências na Formação de Professores. SEC/ UESB - Universidade Estadual do Sudoeste da Bahia. p. 8, 2014. Disponível em: http://institutoateneu.com.br/ojs/index.php/READD/article/view/135/86. ISSN: 23589620. Acesso: 20/03/2017.

KINOSHITA, S.L.; TORRES, R.B.; TAMASHIRO, J.Y.; MARTINS, E.R.F. A Botânica no ensino básico: relatos de uma experiência transformadora. São Carlos: Rima, p. 162, 2006. Disponível em: www.scielo.br/pdf/epec/v13n1/1983-2117-epec-13-0100087.pdf. Acesso em: 03/03/2017

LAJOLO, M. Livro Didático: um (quase) manual de usuário. Brasília: Alberto, ano 16, n. 69, p. 3-9, 1996. Disponível em: http://www.dominiopublico.gov.br/pesquisa/DetalheObraForm.do?select_action=\&co obra=24187. Acesso em: 29/03/2017.

MADALÓZ, R. J.; SCALABRIN, I. S.; JAPPE, M.; O Fracasso Escolar Sob o Olhar Docente: Alguns Apontamentos. IX AMPED SUL - Seminário de Pesquisa em Educação da Região Sul, p. 13, 2012. Disponível em: www.portalanpedsul.com.br/admin/uploads/2012/.../04_16_10_945-7142-1-PB.pdf . Acesso em: 16/03/2017

MENEZES, L.C.; NICOMEDES, M.P.; SOUZA, V.C.; OLIVEORA, A.G.; ANDRADE, R.R.; SILVA, N.A.; SANTOS, B.A.C.; QURIRNO, M.R. Iniciativas para o aprendizado de botânica no ensino médio. In: XI Encontro de Iniciação a Docência, UFPBPRG,2008. Disponível em: http://www.prac.ufpb.br/anais/xenex_xienid/xi_enid/prolicen/ANAIS/Area4/4CFTDCB SPLI C03.pdf> Acesso em 16/03/2017.

MELO E. A; ABREU, F. F.; ANDRADE A. B; ARAÚJO M. I. O. A aprendizagem de botânica no ensino fundamental: dificuldades e desafios. Scientia Plena. v. 8, n. $10.2012 . \quad$ p. $2, \quad$ Disponível em: https://www.scientiaplena.org.br/sp/article/view/492/575. Acesso em: 24/03/2017.

OLIVEIRA, C; MOURA, S. P; SOUSA, E. R. Tic's na Educação: A utilização das Tecnologias da Informação e Comunicação na Aprendizagem do Aluno. Pedagogia em ação. v. 7, n. 1. p. 21, 2015. Disponível em: periodicos.pucminas.br/index.php/pedagogiacao/article/viewFile/11019/8864. Acesso em: 20/03/2017.

OLIVEIRA, T. T. Uso de Tics. no Ensino de Biologia: um olhar docente. Universidade Tecnológica Federal do Paraná Diretoria de Pesquisa e PósGraduação Especialização em Educação: Métodos e Técnicas de Ensino. ParanáPR. $\quad$ p. 35, 2013. Disponível em: repositorio.roca.utfpr.edu.br/jspui/bitstream/1/.../1/MD_EDUMTE_2014_2_128.pdf. Acesso em: 21/03/2017 
SILVA, F. S. S.; MORAIS, L. J. O.; CUNHA, I. P. R. Dificuldades dos Professores de Biologia em Ministrar aulas práticas em escolas públicas e privadas do município de Imperatriz (MA). Revista UNI. Imperatriz (MA), v. 1, n.1, p.135-149, 2011. Disponível em: www.unisulma.edu.br/Revista_UNI_artigo9_p135_149.pdf. Acesso em: 24/03/2017.

SILVEIRA, S. A. Exclusão Digital: a miséria na era da informação. São Paulo: Ed. Fundação Perseu Abramo, p. 46, 2001. Disponível em: http://www.observatoriodaimprensa.com.br/artigos/eno120920011.htm. Acesso em: 20/03/2017.

SOARES M. B. Novas práticas de leitura e escrita: letramento na Cibercultura. Educação e Sociedade. v. 23. n. 81, p. 141-160, 2002. Disponível em: www.scielo.br/pdf/es/v23n81/13935.pdf. Acesso em: 29/03/207.

STAHL, M. Formação de professores para uso das novas tecnologias de comunicação e informação. p. 17, 2000. Disponível em: www.maxwell.vrac.pucrio.br/2030/PROF_NITCS.DOC. Acesso em: 19/06/2016.

THOALDO, D. L. P. B. O uso da tecnologia em sala de aula. Universidade Tuiuti do paraná. Monografia - pós-graduação em Gestão Pedagógica: Educação Infantil e Séries Iniciais, Faculdade de Ciências Humanas, Letras e Artes da Universidade Tuiuti, Curitiba-PR, p. 35, 2010. Disponível em: http://tcconline.utp.br/wpcontent/uploads/2012/04/O-USO-DA-TECNOLOGIA-EM-SALA-DE-AULA.pdf.

Acesso em: 20/03/2017.

ZARANZA, M.T.C. A Rotatividade de Professores na Escola Pública de Ensino Médio do Município de Aracati-Ce: Sentidos Construídos. Universidade do Estado do Rio Grande do Norte - UERN. Faculdade de Educação - FE. Programa de Pós-Graduação em Educação - POSEDUC Mossoró - RN, p. 96, 2014. Disponível em: www.uern.br/controledepaginas/poseduc.../3937maria_thereza_costa_zaranza.pdf. Acesso em: 23/03/2017.

\section{APÊNDICE}

Apêndice A: apresenta o questionário elaborado para a construção de informações desta pesquisa.

\section{CENTRO DE ESTUDOS SUPERIORES DE CAXIAS DEPARTAMENTO DE QUÍMICA E BIOLOGIA DIREÇÃO DO CURSO DE CIÊNCIAS BIOLÓGICAS LICENCIATURA}

\section{APÊNDICE A}

Solicito o preenchimento do questionário a seguir, instrumento de coleta de dados de uma pesquisa que subsidiará a mesma. Sua colaboração será muito importante e o seu anonimato será preservado, assim como, será assegurado o sigilo de suas informações pessoais.

Antecipo agradecimentos.

Atenciosamente, 
Acadêmico Samuel da Silva Carvalho

Prof. Dro. Gonçalo Mendes da Conceição

\section{QUESTIONÁRIO DOS DOSCENTES}

APEDICE A

QUESTIONÁRIO A: PERFIL SOCIOEDUCATIVO

\section{Gênero?}

( ) Masculino

( ) Feminino

2. Qual a sua faixa etária?

( ) 20 a 30 anos.

( ) 31 a 40 anos.

( ) 41 a 50 .

( ) Mais de 50

3. Quanto tempo você já leciona?

( ) 1 a 10 anos.

( ) 10 a 20 anos.

( ) 20 a 30 .

( ) 30 a 40

4. Há quanto tempo você ministra aula nesta escola?

( ) 1 a 10 anos.

( ) 10 a 20 anos.

( ) 20 a 30 .

( ) 30 a 40

5. Nas suas aulas você costuma usar somente o livro didático?

( ) Não

( ) $\operatorname{Sim}$

( ) Às vezes

( ) Nunca

6. Que tipos recursos além do livro didático você costuma usar nas suas aulas?

( ) Cartazes

( ) Experimentos 


\section{( ) Computador}

( ) Outros

7. Quais as principais dificuldades encontradas para repassar os conteúdos aos alunos?

( ) Pouco material didático

( ) Atenção dos alunos

( ) Conteúdos complexos

( ) Falta de interesse

8. Como você avalia a utilização dos recursos tecnológicos na escola em que leciona?

( ) Bom

( ) Ruim

( ) Regular

( ) Péssimo

9. Os professores de Biologia da sua escola utilizam recursos auxiliares para ministrar as aulas?

( ) Sempre

( ) Nunca

( ) Semanalmente

( ) Mensalmente

10. Como você avalia sua escola do ponto de visto pedagógico, quanto à utilização de recursos multimídias?

( ) Bom

( ) Ruim

( ) Regular

( ) Péssimo 